\title{
Retrivability in The Danish National Hospital Registry of HIV and hepatitis $B$ and $C$ coinfection diagnoses of patients managed in HIV centers 1995-2004
}

\author{
Niels Obel*1, Hanne Reinholdt ${ }^{2}$, Lars H Omland ${ }^{1}$, Frederik Engsig1, \\ Henrik T Sørensen ${ }^{3,4}$ and Ann-Brit E Hansen ${ }^{1,5}$
}

\begin{abstract}
Address: ${ }^{1}$ Department of Infectious Diseases, Copenhagen University Hospital, Rigshospitalet, Copenhagen, Denmark, ${ }^{2}$ Research Service Unit, National Board of Health, Copenhagen, Denmark, ${ }^{3}$ Department of Clinical Epidemiology, Aarhus University Hospital, Aarhus, Denmark, ${ }^{4}$ Department of Epidemiology, Boston University, Boston, Massachusetts, USA and ${ }^{5}$ Department of Infectious Diseases, Odense University Hospital, Odense, Denmark

Email: Niels Obel* - niels.obel@rh.regionh.dk; Hanne Reinholdt - hre@sst.dk; Lars H Omland - omland@dadlnet.dk; Frederik Engsig - fren74@gmail.com; Henrik T Sørensen - hts@dce.au.dk; Ann-Brit E Hansen - ann-brit.eg.hansen@rh.regionh.dk

* Corresponding author
\end{abstract}

Published: 25 April 2008

BMC Medical Research Methodology 2008, 8:25 doi:10.1 186/147I-2288-8-25

This article is available from: http://www.biomedcentral.com/I47/-2288/8/25

(C) 2008 Obel et al; licensee BioMed Central Ltd.

This is an Open Access article distributed under the terms of the Creative Commons Attribution License (http://creativecommons.org/licenses/by/2.0), which permits unrestricted use, distribution, and reproduction in any medium, provided the original work is properly cited.
Received: 29 August 2007

Accepted: 25 April 2008

\begin{abstract}
Background: Hospital-based discharge registries are used increasingly for longitudinal epidemiological studies of HIV. We examined completeness of registration of HIV infections and of chronic hepatitis B (HBV) and hepatitis C (HCV) coinfections in the Danish National Hospital Registry (DNHR) covering all Danish hospitals.

Methods: The Danish HIV Cohort Study (DHCS) encompasses all HIV-infected patients treated in Danish HIV clinics since I January 1995. All 2,033 Danish patients in DHCS diagnosed with HIVI during the 10-year period from I January 1995 to 3I December 2004 were included in the current analysis. We used the DHCS as a reference to examine the completeness of HIV and of HBV and HCV coinfections recorded in DNHR. Cox regression analysis was used to estimate hazard ratios of time to diagnosis of HIV in DNHR compared to DHCS.

Results: Of the 2,033 HIV patients in DHCS, a total of 2,006 (99\%) were registered with HIV in DNHR. Of these, I,888 (93\%) were registered in DNHR within one year of their first positive HIV test. A CD4 $<200$ cells $/ \mu \mathrm{l}$, a viral load $>=100,000$ copies $/ \mathrm{ml}$ and being diagnosed after I January 2000 , were associated with earlier registration in DNHR, both in crude and adjusted analyses. Thirty $(23 \%)$ HIV patients registered with chronic HBV $(n=129)$ in DHCS and I $26(48 \%)$ of HIV patients with HCV $(n=264)$ in DHCS were registered with these diagnoses in the DNHR. Further 17 and 8 patients were registered with HBV and HCV respectively in DNHR, but not in DHCS. The positive predictive values of being registered with HBV and HCV in DHCS were thereby estimated to 0.88 and 0.97 and in DNHR to 0.32 and 0.54 .
\end{abstract}

Conclusion: The study demonstrates that secondary data from national hospital databases may be reliable for identification of patients diagnosed with HIV infection. However, the predictive value of co-morbidity data may be low. 


\section{Background}

Since the first AIDS cases were reported, AIDS and HIV infection have been the subject of a wide spectrum of epidemiologic studies [1-3]. The characteristics of HIV infection make it both ideal and highly relevant for epidemiological research: valid diagnostic tools, welldescribed risk factors, unambiguous disease outcomes, a high impact on morbidity and mortality, worldwide dissemination, and huge economic consequences commanding the attention of national and international leaders.

During recent decades, patient registration in computerized hospital database systems has become common [1]. Although they are not designed primarily for epidemiological studies, such hospital-based registries are often used as a quick, convenient way to create huge datasets for epidemiological studies of multiple outcomes $[4,5]$. However their data may not always be entirely accurate or complete.

Due to shared routes of infection, many HIV-infected patients are coinfected with hepatitis B (HBV) or hepatitis $\mathrm{C}(\mathrm{HCV})$. Coinfection with these viruses, especially with $\mathrm{HCV}$, is a strong prognostic marker for effectiveness of antiretroviral treatment [6,7]. Furthermore, HBV and HCV coinfection may influence the timing and choice of antiretroviral treatment. In prognostic studies of HIV, it is thus important to include HBV and HCV status, both to predict prognosis in patient subgroups [8] and to adjust for confounding [9].

The present study quantified the completeness of registration of diagnoses of HIV infection and of chronic HBV and HCV coinfections in the Danish National Hospital Registry (DNHR), based on a comparison with data collected by the Danish HIV Cohort Study (DHCS).

\section{Methods}

\section{Setting}

As of 1 January 2007 Denmark had a population of 5,447,084 (Statistics Denmark), with an estimated HIV prevalence of $0.07 \%$ among adults [10]. Medical care, including antiretroviral treatment, is tax-paid and provided free-of-charge to all HIV-infected residents of Denmark. Treatment of HIV infection is restricted to eight specialized medical centres, where patients are seen on an outpatient basis at intended intervals of 12 weeks. During our study's follow-up period, national criteria for initiating highly active antiretroviral treatment (HAART) were HIV-related disease, acute HIV infection, pregnancy, CD4 cell count $<300$ cells $/ \mu$ l, and, until 2001, plasma HIVRNA > 100,000 copies/ml.

\section{Study population and data collection Study subjects}

DHCS encompasses all HIV-infected patients treated in the above described Danish HIV clinics since 1 January 1995. Patients are identified from the lists of HIV patients in the eight medical centres, as well as from local datasources in these centers of patients tested for HIV RNA and/or CD4 cell counts. Because HIV patients undergo tests for HIV-RNA and CD4 count in the centers at least once a year, the risk of DHCS failing to capture HIVinfected patients seen in the centres is negligible. Further the fact that antiretroviral treatment is in Denmark restricted to these eight clinics ensures that very few patients diagnosed with HIV remains unrecognised by DHCS. In Denmark treatment with antiretroviral drugs is restricted to the eight medical centers participating in DHCS. DHCS has been described elsewhere [10]. The date of HIV diagnosis, dates of AIDS-defining diseases and $\mathrm{HBV}$ and HCV status, are registered for each patient in DHCS as well as AIDS defining events, antiretroviral treatment, HIV-RNA, CD4 counts etc. The data in DHCS are updated on a yearly basis by research nurses or physicians. HBV and HCV status are reviewed by a trained physician or study nurse at the centres to ensure data quality.

The present study includes all 2,033 DHCS patients who met the following criteria: residence in Denmark at diagnosis (i.e., recorded in the Danish Civil Registration System), diagnosed with HIV after 31 January 1994 and before 1 January 2005, and age 16 years or older at time of diagnosis. Patients positive for the hepatitis-B S antigen on screening are categorised as having chronic HBV in DHCS. Patients positive for HCV serology and/or with positive HCV RNA are categorised as HCV patients.

\section{DNHR}

Hospitalisation data for study subjects were obtained from DNHR, which was established in 1977 mainly for administrative and management purposes [11]. This registry includes primary diagnosis as well as co-morbidities [ICD-8 codes until the end of 1993, ICD-10 codes thereafter (ICD-9 has never been used in Denmark)] and procedure codes for patients treated in Danish hospitals. Diagnoses are coded by the hospital physicians at discharge for inpatients and at the initial consultation for the outpatients. Starting on 1 January 1995, the registry was expanded to include outpatients. As the current study is limited to patients diagnosed after 31 December 1994, only ICD-10 codes were relevant. The first date on which a patient was admitted to or seen as an outpatient at a Danish hospital with one of the following diagnosis codes was defined as the DNHR diagnosis date:

HIV: B20.0-B24.9 
Chronic hepatitis B: B18.0 or B18.1

Chronic hepatitis C: B18.2

In a sensitivity analysis we expanded these groups to include nonspecific viral hepatitis as follows:

Chronic hepatitis $B$ and nonspecific chronic viral hepatitis: B18.0, B18.1, B18.8, B18.9

Chronic hepatitis $\mathrm{C}$ and nonspecific chronic viral hepatitis: B18.2, B18.8, B18.9

\section{Statistical analysis}

The numbers of study patients registered with HIV in DNHR and with HBV or HCV coinfection in DNHR and in DHCS were determined. We calculated the completeness (as a measure of sensitivity) of DNHR data as the number of HIV patients recorded with a diagnosis in DNHR divided by the number of patients registered with the diagnosis in DHCS (the reference) [12]. We were not able to compute the predictive value of a HIV diagnosis in the DNHR since we did not have permission from the Danish Data Protection Agency to identify HIV cases recorded only in the DNHR.

Kaplan-Meier analyses were used to construct time-toevent curves. Time was calculated as time elapsed from the DHCS HIV diagnosis date to the registration date of the first HIV diagnosis in DNHR. For patients not registered with HIV in DNHR, time was calculated from the DHCS date of HIV diagnosis to death or to 1 January 2007 (date of last observation in DNHR), whichever came first. [No one was diagnosed with HIV after death in either DNHR or DHCS]. In a few cases the patient was registered with HIV in DNHR before the diagnosis was registered in DHCS, which would give negative time in time to event analysis. In these cases for technically reasons time from registration in DHCS to registration in DNHR was defined to zero.

Cox regression analysis was used to estimate hazard ratios (HR) as a measure of the relative risk of being registered with an HIV diagnosis in DNHR. The assumption of proportional hazards was assessed graphically. Age ( $>40$ years vs. $<=40$ years), CD 4 count ( $>=200$ vs. $<200$ cells/ $\mu \mathrm{l})$ and HIV-RNA $\left(>=10^{5} \mathrm{vs} .<10^{5}\right.$ copies $\left./ \mathrm{ml}\right)$ at diagnosis, gender, route of infection, centre and calendar time (diagnosed before vs. on or after 1 January 2000) were included in the analysis as categorical variables.

Patients registered in DNHR within three months of the date of their first HIV diagnosis according to DHCS were categorized as early registrations. Patients registered in DNHR more than three months after DHCS registration were considered late registrations. The mortality rate ratio (MRR) for the post three-month period was calculated for this group compared with the patients diagnosed later.

Data analysis was performed using SPSS statistical software, Version 15.0 (Norusis; SPSS Inc., Chicago, Illinois, USA). The study was approved by the Danish Data Protection Agency.

\section{Results}

Our study included the 2,033 Danish patients diagnosed with HIV-1 according to DHCS during the 10 -year period from 1 January 1995 to 31 December 2004. Baseline characteristics are shown in Table 1 . Of these, a total of 2,006 (99\%) were registered in DNHR with HIV (Table 2) and 1,888 (93\%) were registered in DNHR within one year of the first positive HIV-1 test (Figure 1). Twenty-four (1.2\%) patients were diagnosed with HIV in DNHR more than one year before registration in DHCS. In the DHCS population, $96 \%$ of patients were seen in one of the eight HIV treatment centres within one year of HIV diagnosis.

\section{Predictors of registration of HIV diagnosis in DNHR}

Being diagnosed after 1 January 2000 or with a baseline CD4 $<200$ cells $/ \mu$ or HIV-RNA $>=100,000$ copies $/ \mathrm{ml}$ were associated with increased change of registration of HIV diagnosis in DNHR, both in crude and adjusted analyses (Table 3). In the adjusted analysis, female gender was associated with an HIV diagnosis appearing earlier in DNHR. Route of infection, age, race and treatment centre did not have a major impact on the likelihood of being registered in DNHR.

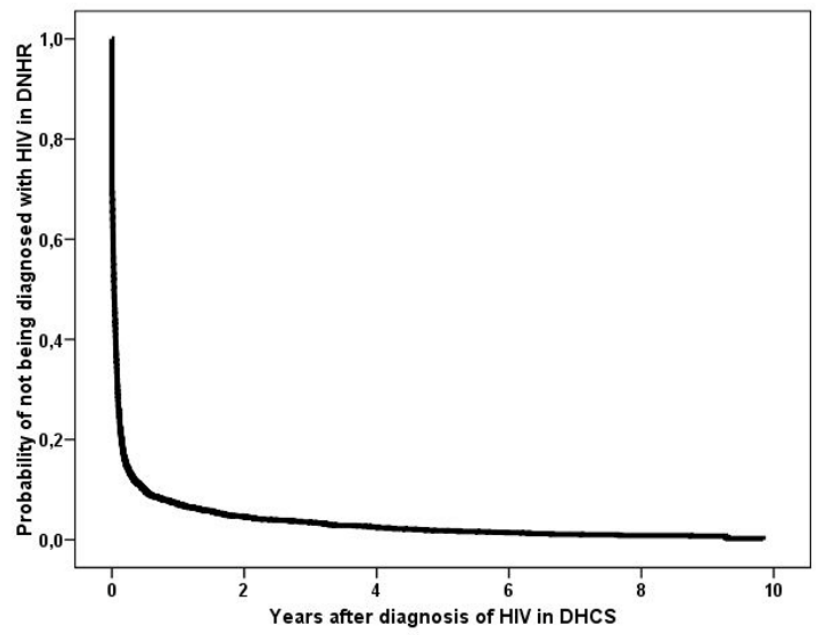

Figure I

Kaplan-Meier curve of time to registration with an HIV diagnosis in the Danish National Hospital Registry from the date of first HIV positive test, according to the Danish HIV Cohort Study. 
Table I: Characteristics of HIV patients registered in the Danish HIV Cohort Study.

\begin{tabular}{ll}
\hline Total number of patients & 2,033 \\
Male (\%) & $\mathrm{I}, 496(73.6)$ \\
Age (years, median, IQR) & $36.4(30.1-44.8)$ \\
Race & \\
$\quad$ Caucasian (\%) & $\mathrm{I}, 530(75.3)$ \\
Black (\%) & $33 \mathrm{I}(16.3)$ \\
Asian (\%) & $\mathrm{III}(5.5)$ \\
$\quad$ Other and unknown (\%) & $6 \mathrm{I}(3.0)$ \\
Route of infection & \\
Homosexual (\%) & $822(40.4)$ \\
Heterosexual (\%) & $908(44.7)$ \\
Intravenous drug use (\%) & $180(8.9)$ \\
Other/unknown (\%) & $123(6.1)$ \\
CD4 count/ul at diagnosis (median, IQR) & $290(110-490)$ \\
Log (HIV-RNA/ml) at diagnosis (median, IQR) & $4.71(3.97-5.30)$
\end{tabular}

\section{Registration and mortality}

To investigate the potential association between early registration in DNHR and mortality, we compared mortality among patients with a diagnosis in DNHR within 3 months of a diagnosis in DHCS with mortality among those diagnosed later. There was no statistically significant difference in risk of death in the group registered early vs. the group registered late (Figure 2, MRR $=0.87: 95 \% \mathrm{CI}$, $0.61-1.24)$.

\section{Hepatitis B and C}

Details of HBV and HCV registration in DNHR and DHCS are provided in Table 2. Only 30 (23\%) HIV patients documented to have chronic HBV in DHCS $(\mathrm{n}=129)$, and $126(48 \%)$ HIV patients documented to have HCV in DHCS $(n=264)$ were registered with these diagnoses in DNHR. Of note, 17 patients were registered with HBV (ICD10: B18.0 and B18.1) and 8 with HCV (ICD10: B18.2) in DNHR who did not have a corresponding record in DHCS (table 2). Assuming that the correct numbers of HBV and HCV are $129+17=146$ and $264+8=$
272 , the positive predictive values of being registered with HBV and HCV in DHCS were 0.88 and 0.97 and in DNHR 0.32 and 0.54 respectively.

In a sensitivity analysis, we categorized patients registered with HBV or nonspecific hepatitis as diagnosed with HBV and patients registered with HCV or nonspecific hepatitis as diagnosed with HCV. However, even when these diagnoses were combined, HBV and HCV remained incompletely documented in DNHR compared to DHCS (Table 2).

The registration in DNHR of chronic hepatitis infections for the 2,033 HIV patients in DHCS increased over time. $26 \%$ and $42 \%$ of all DHCS-established HBV and HCV coinfections were registered in DNHR in the 1995-1999 period, versus $41 \%(\mathrm{p}=0.05)$ and $57 \%(\mathrm{p}=0.01)$, respectively, for the 2000-2004 period.

\section{Discussion}

We found almost complete registration of HIV diagnoses in DHNR. In contrast, co-infection with HBC and HCV were poorly captured.

A unique opportunity to compare two independent, nationwide registries of HIV infection allowed this study to be undertaken. The population-based DHCS was used as a reference to validate the number of HIV diagnoses in DNHR. We documented that DNHR effectively captures the diagnosis of HIV in all patients with at least one contact with an HIV hospital treatment centre. The level of completeness was close to $100 \%$, with more than $90 \%$ of patients registered in DNHR within a year of their first HIV-positive test being documented in DHCS.

One study limitation is the unknown number of persons diagnosed with HIV who have not sought hospital care. Thus, while we can conclude that HIV patients with a hos-

Table 2: Registrations of HIV, chronic hepatitis B, and chronic hepatitis C infections in the Danish National Hospital Registry (DNHR) for 2,033 HIV patients identified in the Danish HIV Cohort Study (DHCS).

\begin{tabular}{|c|c|c|c|c|}
\hline & $\begin{array}{l}\text { Registered with the disease } \\
\text { in DHCS and DNHR }\end{array}$ & $\begin{array}{l}\text { Registered with the disease } \\
\text { in DHCS but not in DNHR }\end{array}$ & $\begin{array}{l}\text { Registered with the disease } \\
\text { in DNHR but not in DHCS }\end{array}$ & $\begin{array}{c}\text { Not registered with the } \\
\text { disease in either DHCS or } \\
\text { DNHR }\end{array}$ \\
\hline HIV & $2,006(99 \%)$ & $27(1 \%)$ & Not applicable & Not applicable \\
\hline $\begin{array}{l}\text { Chronic hepatitis B (BI8.0, } \\
\text { B|8.I)* }\end{array}$ & $30(23 \%)$ & 99 (77\%) & 17 & 1,887 \\
\hline $\begin{array}{l}\text { Chronic hepatitis B } \\
\text { including B } 8.8 \text { and } B \mid 8.9^{*}\end{array}$ & 42 (33\%) & 87 (67\%) & 30 & $\mathrm{I}, 874$ \\
\hline $\begin{array}{l}\text { Chronic hepatitis C } \\
(\mathrm{B} \mid 8.2)^{*}\end{array}$ & $126(48 \%)$ & 138 (52\%) & 8 & $I, 76 \mid$ \\
\hline $\begin{array}{l}\text { Chronic hepatitis C } \\
\text { including } B \mid 8.8 \text { and } B \mid 8.9^{*}\end{array}$ & $129(49 \%)$ & $135(5 \mid \%)$ & 28 & $|, 74|$ \\
\hline
\end{tabular}

* Refers to the ICD-IO codes used to identify patients in DNHR.

The percentage is based on the total number of patients registered in DHCS. 
Table 3: Relative risk (hazard ratio [HR]) of being registered with HIV in the Danish National Hospital Registry according to characteristics and treatment centre.

\begin{tabular}{|c|c|c|}
\hline & Crude HR $(95 \% \mathrm{Cl})$ & Adjusted HR $(95 \% \mathrm{Cl})$ \\
\hline Male gender (reference) & 1 & 1 \\
\hline Female gender & $1.05(0.95-1.16)$ & $1.15(1.02-1.30)$ \\
\hline Caucasian (reference) & I & I \\
\hline Non-Caucasian & $1.02(0.92-1.13)$ & $0.93(0.82-1.05)$ \\
\hline Age $>40$ years (vs. $<=40$ years) & $1.12(1.02-1.22)$ & $1.07(0.97-1.18)$ \\
\hline CD4 count $<200$ cells $/ \mu \mathrm{l}(\mathrm{vs} . \geq 200 \mathrm{cell} / \mu \mathrm{l})$ & $1.45(1.32-1.59)$ & $1.38(1.25-1.52)$ \\
\hline Viral load > 100,000 copies/ml (vs. $\leq 100,000$ copies $/ \mathrm{ml}$ ) & $1.32(1.21-1.45)$ & $1.14(1.03-1.26)$ \\
\hline Heterosexual (reference) & I & I \\
\hline Homosexual & $1.01(0.92-1.11)$ & $1.04(0.93-1.17)$ \\
\hline Intravenous drug use & $0.85(0.72-1.00)$ & $0.87(0.73-1.04)$ \\
\hline Other/unknown & $1.05(0.86-1.27)$ & $1.07(0.88-1.31)$ \\
\hline Diagnosed before year 2000 (reference) & 1 & I \\
\hline Diagnosed after I January 2000 & $1.40(1.28-1.53)$ & $1.40(1.28-1.53)$ \\
\hline \multicolumn{3}{|l|}{ Centre } \\
\hline Center I & 1 & 1 \\
\hline Center 2 & $1.03(0.93-1.14)$ & $1.06(0.95-1.17)$ \\
\hline Center 3 & $1.08(0.91-1.27)$ & $1.12(0.94-1.32)$ \\
\hline Center 4 & $0.87(0.75-1.02)$ & $0.91(0.78-1.07)$ \\
\hline Center 5-8* & $0.99(0.86-1.15)$ & $0.98(0.83-1.14)$ \\
\hline
\end{tabular}

* The four smallest centers in the Danish HIV Cohort Study (DHCS)

pital contact are captured by DNHR, we cannot use DNHR to determine the total number of Danish patients diagnosed with HIV. However, as nearly $95 \%$ of the patients in DHCS are seen in an HIV treatment centre within a year of HIV diagnosis, we assume that this bias is small. Twenty-four patients had a HIV diagnosis captured in the

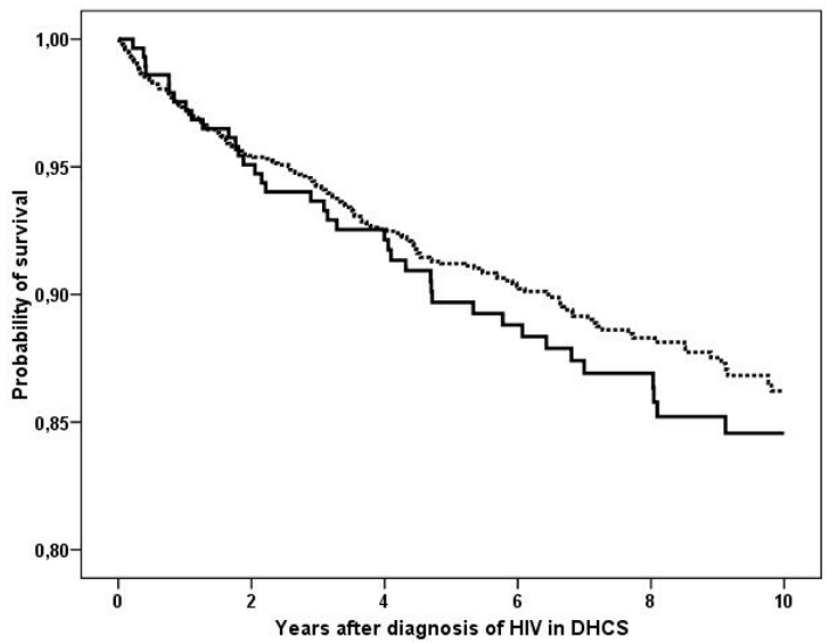

Figure 2

Kaplan-Meier curve of the time to death for patients with diagnoses registered early in the Danish National Hospital Registry [within 3 months of HIV diagnosis in the Danish HIV Cohort Study] [broken line] and for patients diagnosed later (after 3 months) [solid line].
DNHR more than one year before registration in DHCS. This is not surprising, as clinical experience shows that not all patients disclose a previous HIV diagnosis when they present to an HIV treatment centre. Also some of these patients may be misclassified in DHCS.

As mentioned, we did not have permission to identify HIV cases recorded only in DNHR, and thus it was not within the aim of this study to validate the predictive value of an HIV-diagnosis recorded in DNHR. We consider this an acceptable limitation as the positive predicted value is expected to be high. HIV is unambiguously diagnosed by presence of specific antibodies detected by well-validated assay and reports of patients falsely diagnosed with HIV in Danish Hospitals are extremely rare.

Registration of HIV in DNHR was influenced slightly by demographic and HIV-associated factors. Thus, patients with signs of more advanced HIV disease (higher viral load and lower CD4 count at presentation), and patients diagnosed in later years were more likely to be registered in DNHR. Because very few HIV patients are not registered in DNHR, this bias should have little influence on estimates of disease severity based on data from DNHR. Of not, there was no significant differences in mortality in patients registered late compared with patients registered early in DNHR indicating that the probability of being registered in DNHR is not associated with risk of subsequent death. 
The completeness of HIV registration is comparable to the completeness of registration in hospital databases of acute myocardial infarction, severe bacterial infections, cancer, and major surgical procedures [13-16]. These conditions are all rather easily and unambiguously diagnosed and have important treatment indications.

In contrast to HIV, HBV and HCV were incompletely registered in DNHR and registration trends varied greatly over time. Thus, DNHR is a poor tool for determining both absolute and relative risks of HBV and HCV among HIV-positive persons. There are many potential explanations for this finding. Chronic HBV and HCV are often diagnosed after routine screening, are mainly asymptomatic and do not always require treatment $[17,18]$. Thus HBV and HCV infection may not be an important focus of personnel coding discharge diagnoses. The importance of completeness of data on HCV infection is exemplified in a French study that clearly demonstrated that missing diagnosis of HCV (in this study by lack of HIV serology) introduced considerable bias into a cohort study of HIV and HCV coinfection [19].

Our study makes clear that while DNHR generally has good coverage, the completeness of some specific diagnoses may be insufficient for valid epidemiological research. As important examples, HBV and HCV infections are typically diagnosed secondary to the primary HIV diagnosis and are often missing from DNHR.

This validation study was conducted in a Danish setting. Given the nature of HIV infection, its results may be generalised to other countries with similarly organised health care systems such as other Scandinavian countries.

\section{Conclusion}

In conclusion, our study confirms the importance of considering the quality of available data and the circumstances under which they are collected before conducting registry-based studies. While HIV infection can be accurately identified using secondary data in registry-based studies, medical records or other data sources may be needed to identify specific comorbidities.

\section{Competing interests}

Niels Obel has received research funding from Roche, Bristol-Myers Squibb, Merck Sharp \& Dohme, GlaxoSmithKline, Abbott, Boehringer Ingelheim, Janssen-Cilag and Swedish Orphan. Ann Brit Eg Hansen has received honoraria from GlaxoSmithKline. Hanne Reinholdt, Lars Omland, Frederik Engsig, and Henrik Toft Sørensen have no conflicts of interest.

\section{Authors' contributions}

Conception and design: NO. Acquisition of data: NO, HR, $\mathrm{LHO}, \mathrm{FE}, \mathrm{ABH}$. Analysis and/or interpretation of data: NO, HTS, ABH. Drafting of the manuscript: NO and ABH. Revising the manuscript critically for important intellectual content: HR, LHO, FE, HTS. All authors approved the final version.

\section{Acknowledgements}

Centers in the Danish HIV Cohort Study: Departments of Infectious Diseases at Copenhagen University Hospitals: Rigshospitalet (J Gerstoft, N Obel) and Hvidovre (G Kronborg); Odense University Hospital (C Pedersen); Aarhus University Hospitals: Skejby (CS Larsen) and Aalborg (G. Pedersen); Herning Hospital (A L Laursen); Helsingør Hospital (B Kvinesdal); and Kolding Hospital (A Møller).

\section{References}

I. Bozzette SA, Ake CF, Tam HK, Chang SW, Louis TA: Cardiovascular and cerebrovascular events in patients treated for human immunodeficiency virus infection 2. N Engl J Med 2003, 348:702-7I0.

2. Mocroft A, Ledergerber B, Katlama C, Kirk O, Reiss P, d'Arminio MA Knysz B, Dietrich M, Phillips AN, Lundgren JD: Decline in the AIDS and death rates in the EuroSIDA study: an observational study. Lancet 2003, 362:22-29.

3. Palella FJ Jr., Delaney KM, Moorman AC, Loveless MO, Fuhrer J, Satten GA, Aschman DJ, Holmberg SD: Declining morbidity and mortality among patients with advanced human immunodeficiency virus infection. HIV Outpatient Study Investigators I. N Engl J Med 1998, 338:853-860.

4. Lewden C, Salmon D, Morlat P, Bevilacqua S, Jougla E, Bonnet F, Heripret L, Costagliola D, May T, Chene G: Causes of death among human immunodeficiency virus (HIV)-infected adults in the era of potent antiretroviral therapy: emerging role of hepatitis and cancers, persistent role of AIDS. Int J Epidemiol 2004.

5. Triant VA, Lee H, Hadigan C, Grinspoon SK: Increased Acute Myocardial Infarction Rates and Cardiovascular Risk Factors Among Patients with HIV Disease I. J Clin Endocrinol Metab 2007.

6. Weis N, Lindhardt BO, Kronborg G, Hansen AB, Laursen AL, Christensen PB, Nielsen H, Moller A, Sorensen HT, Obel N: Impact of hepatitis $\mathrm{C}$ virus coinfection on response to highly active antiretroviral therapy and outcome in HIV-infected individuals: a nationwide cohort study I. Clin Infect Dis 2006, 42: | $48|-| 487$.

7. Konopnicki D, Mocroft A, De Wit S, Antunes F, Ledergerber B, Katlama C, Zilmer K, Vella S, Kirk O, Lundgren JD: Hepatitis B and HIV: prevalence, AIDS progression, response to highly active antiretroviral therapy and increased mortality in the EuroSIDA cohort I. AIDS 2005, 19:593-60I.

8. Lohse N, Hansen AB, Pedersen G, Kronborg G, Gerstoft J, Sorensen HT, Vaeth M, Obel N: Survival of persons with and without HIV infection in Denmark, 1995-2005 I. Ann Intern Med 2007, 146:87-95.

9. Hansen AB, Gerstoft J, Kronborg G, Pedersen C, Sorensen HT, Obel $\mathrm{N}$ : Mortality in Siblings of Patients Coinfected with HIV and Hepatitis C Virus I. J Infect Dis 2007, 195:230-235.

10. Lohse N, Hansen AB, Jensen-Fangel S, Kronborg G, Kvinesdal B, Larsen CS, Møller A, Willumsen L, Obel N: Demographics of HIV. I infection in Denmark: Results from The Danish HIV Cohort Study. Scand J Infect Dis 2005, 37:338-343.

II. Andersen TF, Madsen M, Jørgensen J, Mellemkjær L, Olsen JH: The Danish Hospital Register: a valuable source of data for modern health sciences. Dan Med Bull 1999, 46:263-268.

12. Sorensen HT, Sabroe S, Olsen J: A framework for evaluation of secondary data sources for epidemiological research 7 . Int J Epidemiol 1996, 25:435-442.

13. Madsen M, Davidsen M, Rasmussen S, Abildstrom SZ, Osler M: The validity of the diagnosis of acute myocardial infarction in routine statistics: a comparison of mortality and hospital dis- 
charge data with the Danish MONICA registry I. J Clin Epidemiol 2003, 56: 124-I30.

14. Schneeweiss S, Robicsek A, Scranton R, Zuckerman D, Solomon DH: Veteran's affairs hospital discharge databases coded serious bacterial infections accurately I. J Clin Epidemiol 2007, 60:397-409.

15. Sorensen HT, Hansen I, Ejlersen S, Schonheyder HC, Hamburger H, Sabroe S: Identification of cases of meningococcal disease: data quality in two Danish population based information systems during a I4-year period. Int J Risk Saf Med 1995, 7: I79- 189.

16. Sorensen HT: Regional administative health registries as a resource in clinical epidemiology. Int J Risk Saf Med 1997, 10:1-22.

17. Soriano V, Puoti M, Sulkowski M, Cargnel A, Benhamou Y, Peters M, Mauss S, Brau N, Hatzakis A, Pol S, Rockstroh J: Care of patients coinfected with HIV and hepatitis C virus: 2007 updated recommendations from the HCV-HIV International Panel I. AIDS 2007, 21 : 1073-1089.

18. Matthews G: The management of HIV and hepatitis B coinfection I. Curr Opin Infect Dis 2007, 20:16-21.

\section{Pre-publication history}

The pre-publication history for this paper can be accessed here:

http://www.biomedcentral.com/1471-2288/8/25/prepub

Publish with Biomed Central and every scientist can read your work free of charge

"BioMed Central will be the most significant development for disseminating the results of biomedical research in our lifetime. "

Sir Paul Nurse, Cancer Research UK

Your research papers will be:

- available free of charge to the entire biomedical community

- peer reviewed and published immediately upon acceptance

- cited in PubMed and archived on PubMed Central

- yours - you keep the copyright

Submit your manuscript here:

http://www.biomedcentral.com/info/publishing_adv.asp 